\title{
Contraceptive Use among Slum Women in Slums of Dhaka City
}

\author{
Rafia Akter \\ Lecturer \\ Department of Science and Humanities \\ Military Institute of Science and Technology, Bangladesh \\ E-mail: rafiaakter93@gmail.com
}

Received: June 06, 2020

Accepted: July 03, 2020

Online Published: July 20, 2020

doi: I0.4628I/aijssr.v5i3.667

URL: https://doi.org/I0.4628I/aijssr.v5i3.667

\begin{abstract}
Bangladesh has experienced a dramatic increase in contraceptive use and a sensational decline in fertility over 3 decades since its independence. The family planning program (FPP) in Bangladesh has been considered a success story in a setting without much socio-economic development. With the concerted effort of the Government of Bangladesh (GOB) and Non-Governmental Organizations (NGOs), women are becoming aware of physical health; (Icddr,b). In this context, a study has conducted to unveil the scenario of using contraception in the slum area of Dhaka City. In this research, IOI respondents were selected from two selected slums of Dhaka city. This study examines the use of contraceptives among the slum women. Findings revealed that respondents age 15-20) around 8.6\% prefer an oral pill, 2.5\% prefer IUD, 6.2\% prefer condom (husband's method) and $4.9 \%$ prefer injectable. Respondents aged within (2I-25) around 19.8\% prefer oral pill, 3.7\% prefer IUD, $6.2 \%$ prefer condom (husband's method) and $7.4 \%$ prefer injectable. Respondents age (above 25) around 21.0\% prefer oral pill, I.2\% prefer IUD, I.2\% prefer condom (husband's method) and $17.3 \%$ prefer injectable. In total, around $49.4 \%$ prefer an oral pill, $7.4 \%$ prefer IUD, 13.6\% prefer condom and $29.6 \%$ prefer injectable. Women's education, exposure to mass media, current work status husband's working status, age of marriage, decision-making rights, religious restriction are the important determinants of contraceptive use among slum women.
\end{abstract}

Keywords: Contraceptive Methods, Preference, Married Women, Urban Slum.

\section{Introduction}

Bangladesh is a developing nation. As Bangladesh is a densely populated country, Population growth constitutes a primary threat to continued economic growth, social insecurity and development in Bangladesh. Bangladesh is not an exception to its population burden. Despite significant progress in family planning programs, the population of Bangladesh is increasing at an alarming rate. One strategy that has been used to cease further increases infertility in Bangladesh involves using family planning outreach workers who travel throughout rural and urban areas educating women regarding the use of modern contraceptives, and making these available at the doorstep. This family planning program has been operational for over 30 years of independence. The family planning program (FPP) in Bangladesh has been considered a success story in a setting without much socioeconomic development. With the concerted effort of the Government of Bangladesh (GOB) and Non-Governmental Organizations (NGOs), the contraceptive prevalence rate has increased from eight percent in 1975 to 54 percent in $1999-2000$ (Mitra \& Al-Sabir, 1996). The process of population control in Bangladesh has been well documented with testimony at home and abroad. Although the consecutive demographic health surveys conducted in Bangladesh continually showed that the contraceptive prevalence rate was higher in urban areas than the urban areas. However, little is known on the contraceptive use patterns among slum dwellers. The rapid growth of population in the informal settlements and urban squatters suggests the urgent need to examine the contraceptive use and method choice among women living in the urban slums. Bangladesh has experienced dramatic increase of contraceptive use and a sensational decline in fertility over the three decades. The fertility has decreased from 6.3 births in the mid-1970s to 2000 and contraceptive use rate has increased more than seven folds during this period from $7.7 \%$ to $65.8 \%$ (NIPORT, 2012). Although the consecutive Demographic Health Surveys conducted in Bangladesh continually showed that the contraceptive prevalence rate (CPR) was higher in urban than rural areas, however, little 
is known on contraceptive use pattern among slum dwellers. The rapid growth of population in the informal settlements suggests the urgent need to drive up understanding the contraceptive use and method choice among women living in the urban slums.

\section{Objectives of the Research}

The main objectives of "Contraceptive use among women in two selected slums of Dhaka city" are given below

- To examine the socio-demographic background of slum women regarding contraceptive use

- To investigate the factors which are affecting contraceptive use and method choice among slum women

- To explore the ways to remove those obstacles in using contraceptives among slum women.

\section{Literature Review}

Amin, Li, and Ahmed (1996) stated that Participation in credit programs increases women's economic status and empowers women through the experience of group solidarity, increased mobility, access to information about modern contraceptive methods and services, and support from program staff. Due to empowerment, they can make a decision on the use of contraception. Moreover, women's involvement in credit programs increases their interaction outside of the home, as well as outside home, relieving social isolation and exposing them to new role models and behaviors, the adoption of which is reinforced through group membership.

Socioeconomic Factors Associated with Contraceptive Use and Method Choice in Urban Slums of Bangladesh (Kamal, 2009) explored contraceptive use patterns among slum dwellers in Bangladesh. The studies conducted on fertility and contraceptive use are confined to micro level and DHS data and focused mainly on rural women or national level. Little attention has been paid to contraceptive behavior among slum dwellers, where $35 \%$ of the urban people of Bangladesh reside. The principal contribution of this study is to increase the understanding of contraceptive use and method choice among urban poor living in the slums using a nationally representative survey data conducted in 2006. This study shows the comparisons of contraception practices which reveal that the urban poor were more likely to use modern methods than their rural counterparts, where the vast majority of the people of Bangladesh reside. The study also shows that access to mass media played an important role in contraceptive adoption and method choice. The influence was found somewhat stronger for the preference of traditional methods than modern methods among women who were exposed to TV. Media can inform and motivate couples, even about complex subjects such as their reproductive means and goals. Finally, the findings of the study suggest that efforts should be made better educating the slums dwellers, particularly women. Opportunities should be created equally for men and women to provide them formal and informal jobs to reduce poverty in the slums and reduce the sex preference of children. Mass media may play an important role to inspire couples to use modern contraceptive methods. Effective measures should be taken to reduce child mortality in the slum areas, which may further increase the use rate of contraception among the urban poor.

Wahed, Bhuyan, and Rahman (2006) this study conducted on the role of women in decision making on family planning among the slum women in a selected area of Dhaka city. The study revealed that on the aspect of contraceptive method choice women were the program maker. More than one-third of the total women had the self-confidence to take such decisions despite their husband's disapproval. One of the important findings is that a large proportion of slum women (45\%) would like to decide jointly about the number of children they should have. But they could not place birth. Nearly half $(48.4 \%)$ of their first Childs was born accidentally. The study found a significant relationship between respondents' age and in deciding family size. The duration of the marriage of the respondent also emerged as one of the important determinants of deciding family size. It can be told that programmatic efforts alone will not be enough to expedite the improvement of the position of urban slums women. The study findings finally recommended that efforts should be made to enough greater participation of women with their husbands in all family decisions.

Kabir, Islam, and Bapari (2017) the study conducted through quantitative sample survey, this research conducted on Kamlapur, Karwan Bazar and kamrangirchor area in Dhaka city, All the women of a slum area in Dhaka city are the population of the study and each woman is the unit of analysis in this study. The purposive sampling technique used in the present study. Firstly three slums of Dhaka city were selected purposively. This study has conducted to unveil the scenario of using contraception in the slum area of Dhaka city. The study has found that the slum women are using different types of contraceptives like as pill, IUD, injection, condom etc. The studies have found that older women in Bangladesh usually opt for traditional methods, and young women prefer modern contraceptive methods. Study also shows that they suffered from different types of problems including weakness, increasing weights, vomiting, menstrual problems etc. This study using factors which influence the use of the modern contraceptives method of couples: educational qualification of couples, number of children in the family, positive attitude towards modern contraceptives, a higher level of knowledge on contraceptives and males consent regarding family planning. 
Democracywatch (20I4) the objective of this study is to know about the present status, powers and autonomy of women of slum dwellers regarding reproductive decision making. Both the qualitative and quantitative approaches were used to conduct the study including literature review, sample survey and non-participant observation. The sample survey was carried out among the slum dwellers at different places in Dhaka, namely Moghbazar Rail Gate, Vashantek - Mirpur, Rajbari -Shia Masjid, Baoniabadh- Mirpur. Among the slum dwellers, 36I respondents were selected using random sampling method to collect data, of them 280 are female and $8 \mathrm{I}$ are male. This study will also help us to understand government health delivery system in slums, treatment-seeking behavior for various reproductive morbidities (Gynecological, Obstetric and Contraceptive Morbidity) and discuss various homemade remedies women use and treatment- seeking behavior is often influenced by a large number of factors apart from knowledge and awareness.

\section{Research Methodology}

Though the nature of study both quantitative and qualitative approaches are applicable in this research, only the quantitative research method was used in this study. The study was conducted on married women on urban slum to know about their knowledge regarding the factors associated with the use of contraceptives and creating awareness. The study was carried out in urban Dhaka slum. Among the slums of Dhaka city, IOI representative samples of two slums were selected purposively according to access facilities. These are khatalbagan and kamlapur slum. A semi-structured interview schedule was formulated for data collection. A set of independent variables were included in the study, namely, the current age of the women, women's education, women's working status, religion current work status, husband's income, husbands occupation, number of living children, age of first marriage, desire for children, preferable contraceptive methods etc. And a set of dependent variables were included in the study, namely, Religion objections, Type of place of residence, Access to mass media, husband and wife's rights on decision-making process. Involvement with NGO program, location of NGOs near house, number of visits by FP field worker, risk factors associated with contraceptive use, side effects of contraceptives, knowledge and fertility awareness among slum women, Sampling framework also an important part of sample size. Non-probability was used in this study. It is the list of all units in the population from which the sample will be selected. Only one survey instrument was used in the study: the questionnaire. Relevant data on health from secondary sources were also collected to supplement the primary data and relate secondary data sources to the contraceptive use among slum women in Dhaka.

\section{Result and Discussions}

There are few studies on contraceptive use patterns among slum dwellers in Bangladesh. The principal contribution of this study is to drive up the understanding of contraceptive use and method choice among urban poor living in the slums using representative survey data conducted in 2017. Most important data were found in the survey. This study focused on respondents preferred contraceptives for birth control and four major contraceptive methods: oral pills, IDU, condom, injection. Findings showed that majority respondents prefer oral pill as a preferable method of contraception. The study conducted to examine the use of contraceptives among the slum women but also examine the socio-demographic background of slum women in a microlevel and focused mainly on poor urban slum women. A set of independent variables were included in the study, namely, the current age of the women, women's education, women's working status, religion current work status, husband's income, husbands occupation, number of living children, age of first marriage, desire for children, preferable contraceptive methods, etc are the indicators socio-demographic background.

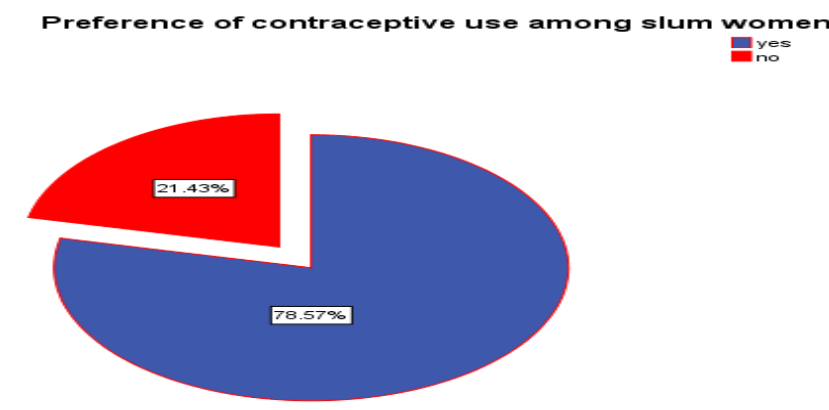

Figure I. Level of preference for contraceptive use 
Findings showed that in figure I, from IOI respondents, $78.6 \%$ preferred to take contraceptive methods and have knowledgeable about it and outcomes. On the other hand, $21.4 \%$ of respondents did not prefer any type of contraceptive method for family planning.

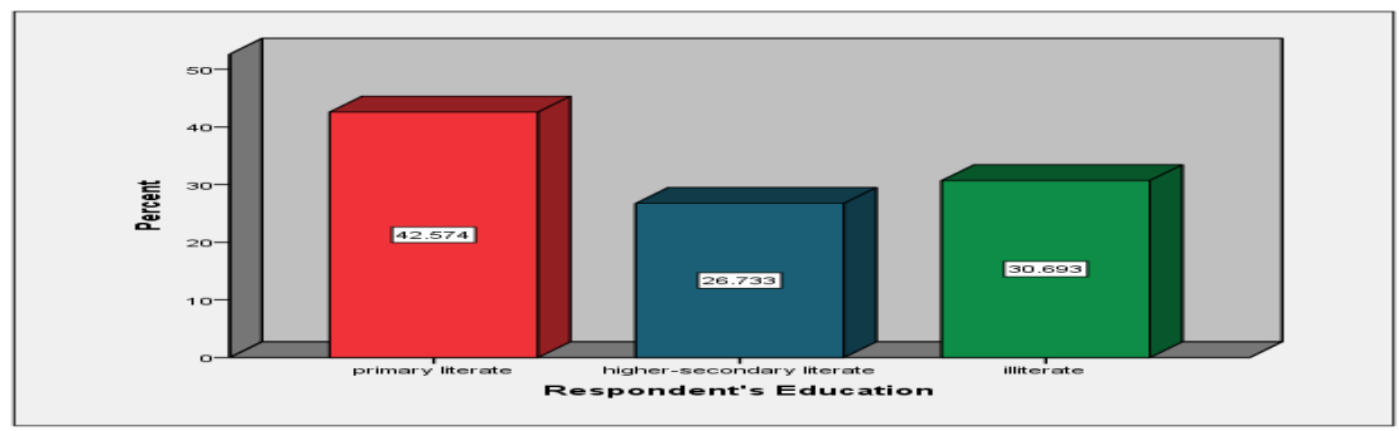

Figure 2. Respondents Education

Education is one of the most crucial indicators of socio-demographic background. Figure 2 showed from IOI respondent's majority $42.6 \%$ received primary education, $30.6 \%$ are illiterate and $26.7 \%$ have received higher-secondary education. The findings of the study reveal that 35\% respondent's age of marriage was less than I5 years and 65\% respondent's age of marriage was less more than 15 in the two selected slums of Dhaka.

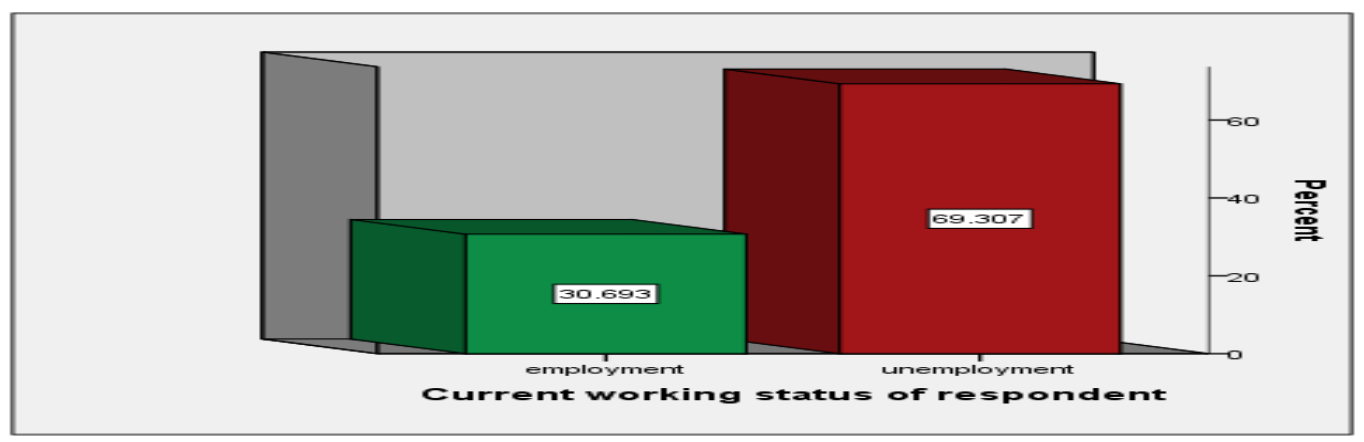

Figure 3. Respondents Working Status

Respondent's working is many influential factors in contraceptive use. According to, figure 3, around $69.3 \%$ of respondents are unemployed and $30.6 \%$ of respondents are employed and have their own decision making rights. From them $78 \%$ have children and $22 \%$ do not conceive any child. From IOI respondents $24 \%$ of couples communicate with each other once or twice and $76 \%$ communicate with each other more often. From $58.02 \%$ consulted with doctor or health workers for contraceptive use, $41.98 \%$ did not prefer to consult with the doctors or health worker

Table I. Preferable contraceptives of slum women

\begin{tabular}{cccccc}
\hline Age & \multicolumn{3}{c}{ Preferable contraceptives of slum women } & \multirow{2}{*}{ Total } \\
\cline { 2 - 5 } & Oral Pill & IUD & Condom & Injection & \\
\hline I5-20 & $8.6 \%$ & $2.5 \%$ & $6.2 \%$ & $4.9 \%$ & $22 \%$ \\
\hline $2 \mathrm{I}-25$ & $\mathrm{I} 9.8 \%$ & $3.7 \%$ & $6.2 \%$ & $7.4 \%$ & $38 \%$ \\
\hline 25 above & $21.0 \%$ & $1.2 \%$ & $1.2 \%$ & $17.3 \%$ & $40 . \%$ \\
\hline Total & $49.4 \%$ & $7.4 \%$ & $\mathrm{I} \% .6 \%$ & $29.6 \%$ & $100.0 \%$ \\
\hline \hline
\end{tabular}


Table I Findings also explore that respondents age with (I5-20) around 8.6\% prefer an oral pill, 2.5\% prefer IUD, $6.2 \%$ prefer condom (husband's method) and $4.9 \%$ prefer inject tables. Respondents aged among (2I-25) around I9.8\% prefer an oral pill, $3.7 \%$ prefer IUD, $6.2 \%$ prefer condom (husband's method) and $7.4 \%$ prefer inject tables. Respondent's age (above 25 ) around $21.0 \%$ prefer an oral pill, I.2\% prefers IUD, I.2\% prefer condom (husband's method) and $17.3 \%$ prefer inject tables. In total, around $49.4 \%$ prefer an oral pill, $7.4 \%$ prefer IUD, $13.6 \%$ prefer condom (the husband's method) and $29.6 \%$ prefer injectable.

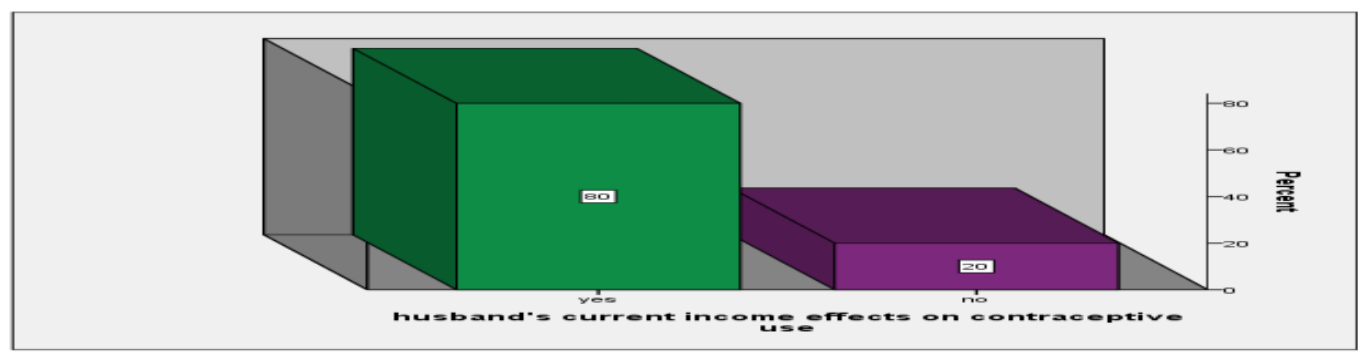

Figure 4. Effect of husband's income

According to (figure 4) $80 \%$ respondents stated that husband's income hardly affects contraceptive method used as the majority respondents are unemployed they dependent on husband's income. $20 \%$ respondents stated husbands income don't effect on contraceptive use

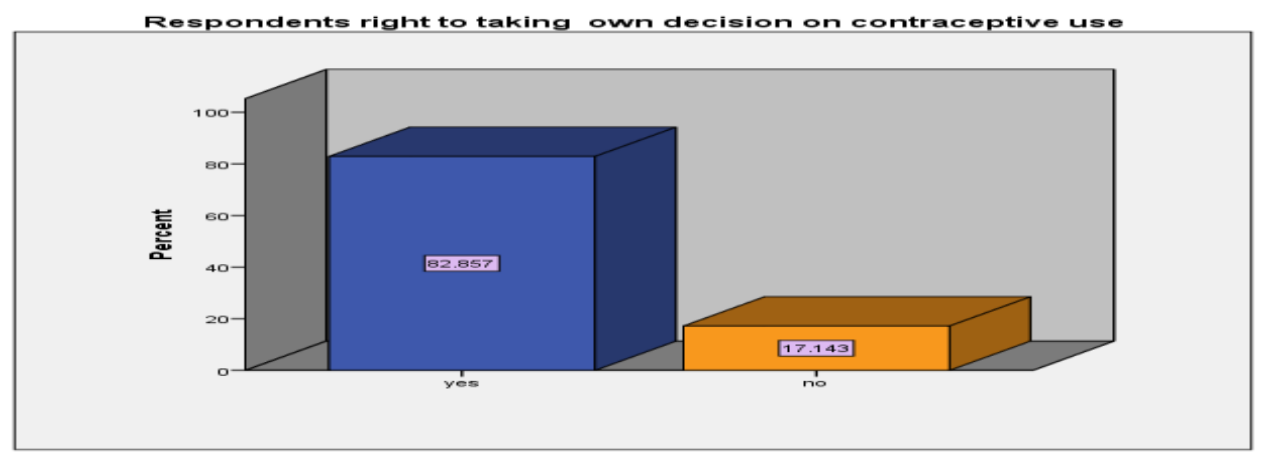

Figure 5. Decision-making rights on contraceptive use

Findings (figure 5) showed that from total respondents, $82.6 \%$ of respondents stated that they have right to taking own decision regarding contraceptive use. $17.1 \%$ of respondents replied that they don't have the right to choose contraceptive methods without their husbands' consent.

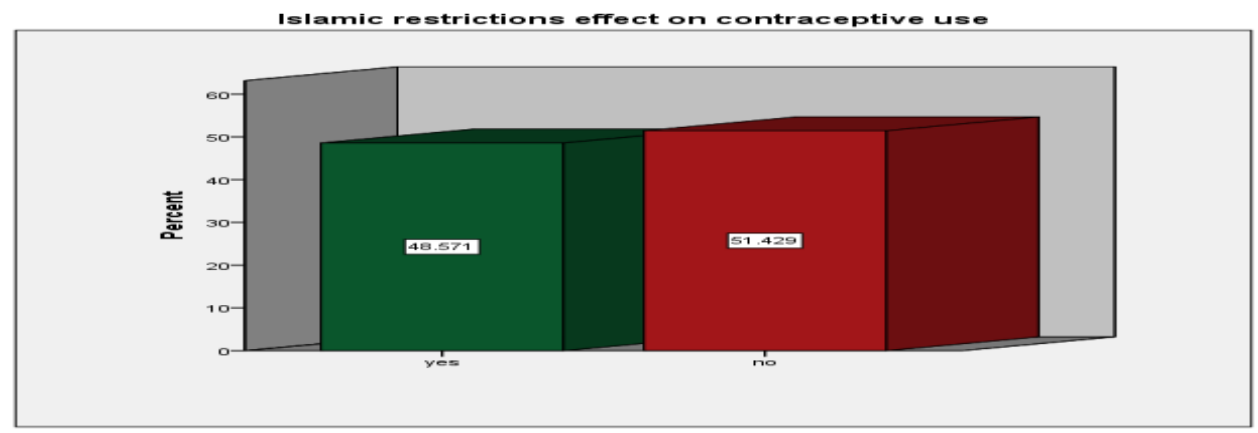

Figure 6. Effect of Islamic restrictions on contraceptive use 
Findings (figure 6) revealed that, Majority 51.4\% don't belief, Islamic restrictions regarding birth control effects on contraceptive use in slum women. But $48.6 \%$ belief that it effects on contractive use. Findings explored that from, IOI respondents $71.4 \%$ stated that they are aware of the side effects of contraceptives. $28.5 \%$ stated they are not aware of its side effects.

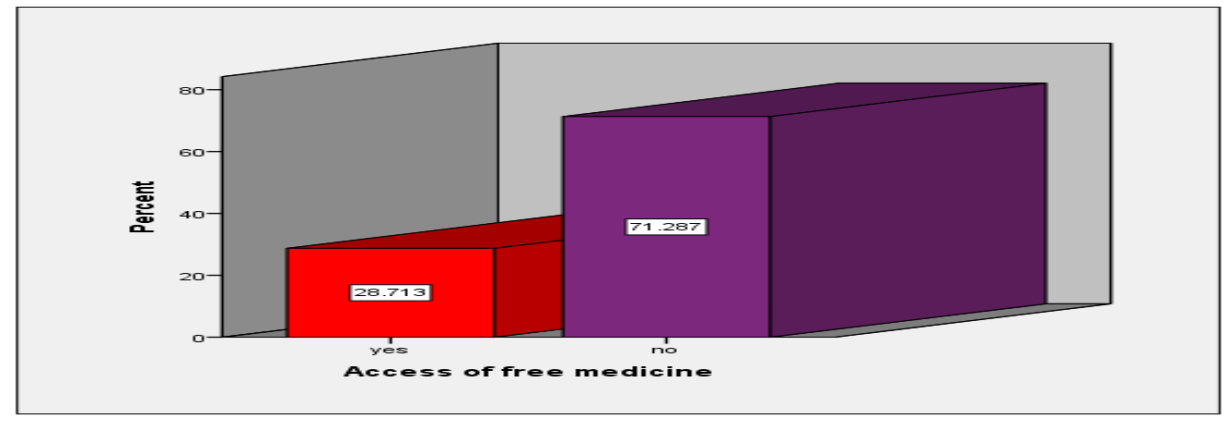

Figure 7. Access to free medicine

This survey (figure 7) revealed that, majority 7I.2\% of respondents stated, they don't have access to free medicines and contraception. $28.7 \%$ stated that they have access to free medicine.

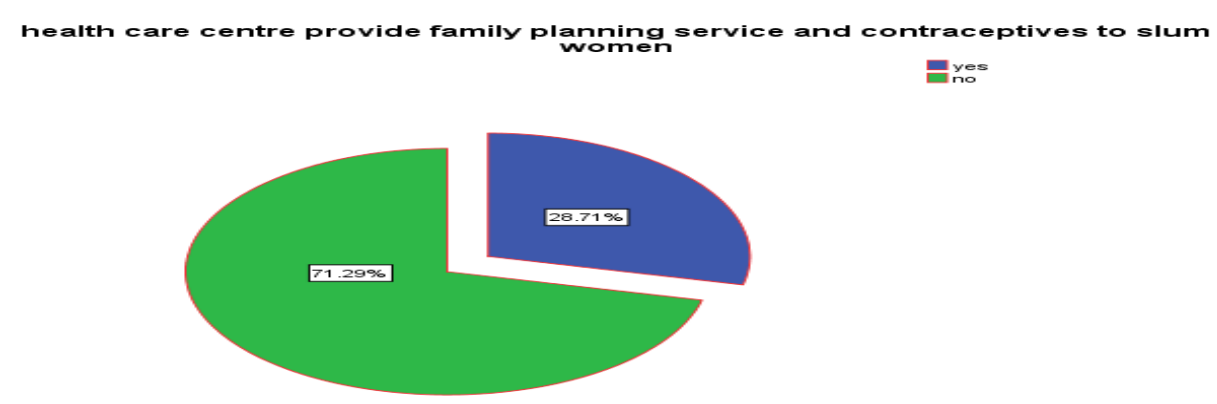

Figure 8. Contribution of health care center regarding contraceptive use

Figure 8 shows that $71.2 \%$ respondents stated that, health care center provide family planning services and contraceptives among slum women. And $28.7 \%$ replied that they don't get any services from health care center. This survey also revealed that, majority 7I.2\% slum women, they don't have access to free medicines and contraception. $28.7 \%$ stated that they have access to free medicine. This survey also explored that, majority $72 \%$ of respondents stated that Radio and television can increase contraceptive use among slum women. $28 \%$ of respondents don't think that.

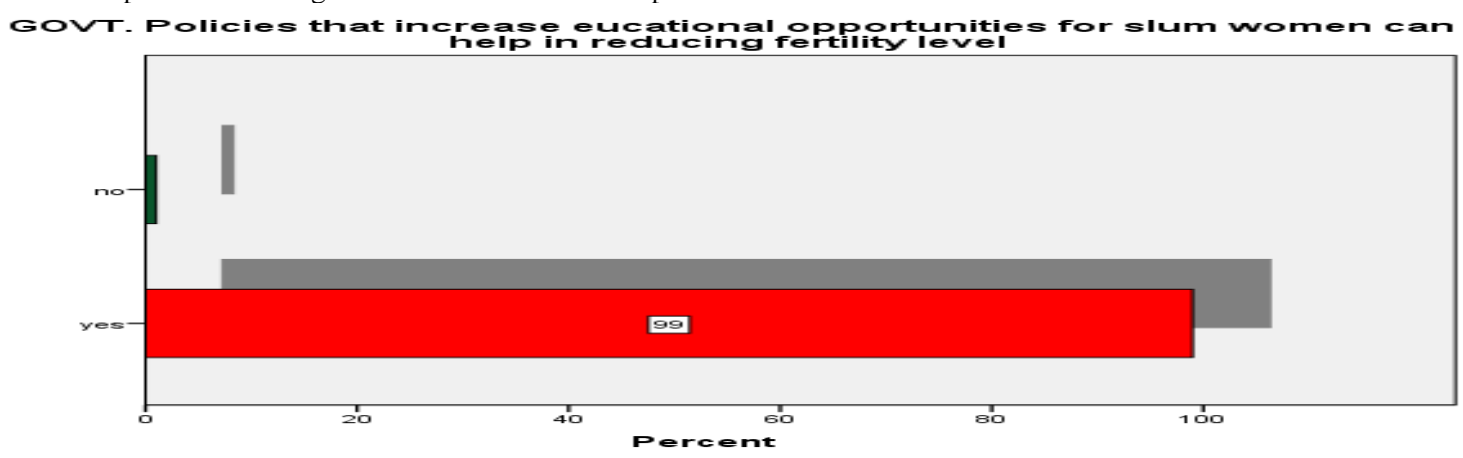

Figure 9. Government policies 
Figure 9 from IOI respondents, 99\% respondents promote that government policies and educational opportunities can reduce fertility rate among slum women.I\% don't promoted that. This study tried to find out the awareness and the decision-making rights of slum women regarding contraceptives rights, NGOs and health care center also have much contribution regarding contraceptive use among slum women. One of the most positive sides of this survey is that women has more decision-making power for preferring contraceptives but still they depend on husbands' income. As majority of the respondents are unemployed still they have to depend on their husband's income.

\section{Conclusion}

Women are living in an urban slum, mostly victims of poor and unhealthy environment. Due to lack of proper education, they don't know self- hygiene and family planning. This study focused on the socio demographic background of slum women and influencing factors of contraceptives use. Women's education, exposure to mass media, current work status husband's working status, age of marriage and Role of health care center are the important determinants that demonstrate highly significant positive relationships with contraceptive use and method choice in the slum- dwelling women of Bangladesh. Women are also experiencing the right to their own decision. This is a positive signs Access to mass media played an important role in contraceptive adoption and method choice. Media can both inform and motivate couples, even about such complex subjects as their reproductive means and goals. NGOs should play important role to adopt modern methods among slum women. The Government should take initiatives and distribute free contraceptives among slum women.

\section{References}

Amin, R., Li, Y., \& Ahmed, A. U. (I996). Women's credit programs and family planning in rural Bangladesh. International Family Planning Perspectives, I58-162.

Democracywatch. (2014). Reproductive Decision Making Role among Slum Dwellers of Dhaka City. Retrieved from https://www.dwatch-bd.org/ggtp/Research\%20Reports/reproductiv.pdf

Kabir, M. A., Islam, M., \& Bapari, M. Y. (2017). A Study on Using Contraception in Dhaka City: A Scenario from Slum Area. Asian Journal of Humanity, Art and Literature, 4(2), I3I-I40.

Kamal, S. M. (2009). Contraceptive use and method choice in urban slum of Bangladesh. In International Conference on Family Planning: Research and Best Practices (Vol. I5, p. I8).

Mitra, S. N., \& Al-Sabir, A. (1996). Contraceptive use dynamics in Bangladesh. Macro International Inc.

National Institute of Population Research, Training (Bangladesh), Mitra and Associates (Firm), \& MEASURE DHS (Program). (2012). Bangladesh Demographic and Health Survey 20II: Preliminary Report. National Institute of Population Research and Training.

Wahed, T., Bhuyan, M. S. A., Rahman, M. Z. (2006). The role of women in decision making on family planning among the slum women in a selected area of Dhaka City. JOPSOM, 25(I), 33-4I

\section{Copyrights}

Copyright for this article is retained by the author(s), with first publication rights granted to the journal. This is an open-access article distributed under the terms and conditions of the Creative Commons Attribution license (http://creativecommons.org/licenses/by/4.0/). 